Check for updates

Cite this: Phys. Chem. Chem. Phys., 2018, 20, 6121

Received 31st December 2017. Accepted 31st January 2018

DOI: $10.1039 / c 7 c p 08703 a$

rsc.li/pccp

\title{
First-principles method for calculating the rate constants of internal-conversion and intersystem-crossing transitions $\dagger$
}

\author{
R. R. Valiev, (D) ${ }^{a b}$ V. N. Cherepanov, ${ }^{a}$ G. V. Baryshnikov (iD ${ }^{\text {ac }}$ and D. Sundholm (iD ${ }^{b}$
}

\begin{abstract}
A method for calculating the rate constants for internal-conversion ( $\left.k_{\mid \mathrm{C}}\right)$ and intersystem-crossing $\left(k_{\mid \mathrm{ISC}}\right)$ processes within the adiabatic and Franck-Condon (FC) approximations is proposed. The applicability of the method is demonstrated by calculation of $k_{\mathrm{IC}}$ and $k_{\mathrm{ISC}}$ for a set of organic and organometallic compounds with experimentally known spectroscopic properties. The studied molecules were pyrromethene-567 dye, psoralene, hetero[8]circulenes, free-base porphyrin, naphthalene, and larger polyacenes. We also studied fac-Alq 3 and fac-Ir(ppy) $)_{3}$ which are important molecules in organic light emitting diodes (OLEDs). The excitation energies were calculated at the multi-configuration quasi-degenerate second-order perturbation theory (XMC-QDPT2) level, which is found to yield excitation energies in good agreement with experimental data. Spin-orbit coupling matrix elements, non-adiabatic coupling matrix elements, Huang-Rhys factors, and vibrational energies were calculated at the time-dependent density functional theory (TDDFT) and complete active space self-consistent field (CASSCF) levels. The computed fluorescence quantum yields for the pyrromethene-567 dye, psoralene, hetero[8]circulenes, fac-Alq 3 and fac-Ir(ppy) 3 agree well with experimental data, whereas for the free-base porphyrin, naphthalene, and the polyacenes, the obtained quantum yields significantly differ from the experimental values, because the FC and adiabatic approximations are not accurate for these molecules.
\end{abstract}

\section{Introduction}

Molecular photophysics is a rapidly developing research area of molecular and chemical physics. ${ }^{1-3}$ Interaction of the electromagnetic radiation with molecules, molecular luminescence properties, and transformations of excited electronic energy into vibrational energy are important photophysical processes. Detailed knowledge about these photophysical properties is needed when designing optical molecular devices such as organic light-emitting diodes, ${ }^{4,5}$ laser applications, ${ }^{6}$ and other devices that convert light energy or other forms of energy. ${ }^{7}$ The mechanism of light-induced processes such as the light absorption of photosynthesis can also be understood by studying the photophysical properties of the chlorophylls and other involved molecules. ${ }^{8}$

Photophysical processes in molecules can be divided into intramolecular and intermolecular ones. ${ }^{9}$ The intermolecular processes play a key role in luminescence quenching and

\footnotetext{
${ }^{a}$ Tomsk State University, 36 Lenin Avenue, Tomsk, Russia.

E-mail:valievrashid@gmail.com

${ }^{b}$ Department of Chemistry, University of Helsinki, A. I. Virtanens plats 1,

P.O. Box 55, FI-00014 Helsinki, Finland

Division of Theoretical Chemistry and Biology, School of Biotechnology,

KTH Royal Institute of Technology, SE-10691 Stockholm, Sweden

$\dagger$ Electronic supplementary information (ESI) available. See DOI: 10.1039/c7cp08703a
}

in deactivating excited electronic states at high molecular concentrations, ${ }^{10}$ whereas the intramolecular processes depend almost completely on the intrinsic properties of the molecule. ${ }^{11}$ Photophysical properties like the quantum yields of fluorescence $\left(\varphi_{\mathrm{fl}}\right)$ and phosphorescence $\left(\varphi_{\text {phos }}\right)$ are determined by the ratio between the rate constants of radiative $\left(k_{\mathrm{r}}\right)$ and nonradiative $\left(k_{\mathrm{nr}}\right)$ intramolecular processes. ${ }^{9,10}$

When a photon is absorbed, molecular systems transfer from the ground state to an excited electronic state, and they can be de-excited via different channels. Radiative deactivation channels comprise emission of a photon with an energy that is smaller than or equal to the excitation energy. Nonradiative channels do not involve any photon emission but the excess energy transfers to vibrational energy leading to an increase of the temperature. Internal conversion (IC) and the intersystem crossing (ISC) are main intramolecular nonradiative processes. ${ }^{9-11}$ The electronic energy in both processes is converted into molecular vibrations. In the case of IC, the spin multiplicity of the molecule is conserved, whereas ISC involves the initial and final states of different spin multiplicities. ${ }^{1}$ The IC process occurs due to nonadiabatic coupling interactions. ISC is caused by the spin-orbit coupling interaction. When the concentration of molecules is low, it can be assumed that the total rate constant for the nonradiative process is the sum of the rate 
constants of the two channels $k_{\mathrm{nr}}=k_{\mathrm{IC}}+k_{\mathrm{ISC}}$, where $k_{\mathrm{IC}}$ and $k_{\mathrm{ISC}}$ are the rate constants for IC and ISC, respectively. ${ }^{9,12}$ The total rate constant for the nonradiative process $k_{\mathrm{nr}}$ can be estimated experimentally from the quantum yields $\left(\varphi_{\mathrm{fl}}, \varphi_{\mathrm{phos}}\right)$ and from the rate constant of the radiative processes $\left(k_{\mathrm{r}}\right) \cdot{ }^{9,10}$ However, the experimental determination of $k_{\mathrm{IC}}$ and $k_{\mathrm{ISC}}$ is very difficult. ${ }^{13,14}$ The rate constants for the radiative transitions can be calculated quantum chemically ${ }^{15-17}$ employing nonadiabatic molecular dynamics simulations at ab initio levels of theory ${ }^{18-22}$ or by using specific approximations considering empirical corrections. $^{1,15,23}$ Molecular dynamics simulations are computationally expensive, which limits their application to smaller molecular systems. The semiempirical approach by Plotnikov, Artyukhov and Maier, which is based on the incomplete neglected differential overlap (INDO) method with a spectroscopic parameterization, can be used for calculating the photophysical properties of large organic molecules. ${ }^{24-31}$ Maier and Artyukhov employed computational methods based on the theory developed by Robinson, Jortner ${ }^{11}$ and Plotnikov ${ }^{24}$ to estimate $k_{\text {IC }}$ and $k_{\text {ISC }}$ at the INDO level of theory. ${ }^{25-28}$ They calculated the matrix elements of the nonadiabatic coupling and spin-orbit coupling operators for the singlet and triplet electronic states at the INDO level of theory, whereas the vibrational integrals were estimated from the experimental spectroscopic data. The INDO approach renders routine calculations of $k_{\mathrm{IC}}$ and $k_{\mathrm{ISC}}$ for large organic molecules consisting of up to 200 atoms feasible.

However, the semiempirical INDO approach of Artyukhov and Maier can be applied only to molecules consisting of light atoms such as $\mathrm{H}, \mathrm{C}, \mathrm{N}, \mathrm{O}, \mathrm{F}, \mathrm{S}$, and $\mathrm{Cl}$, whereas it cannot be employed in studies of photophysical properties of organometallic compounds. The semiempirical method has also been found to lead to large errors in the rate constants $k_{\mathrm{IC}}$ and $k_{\mathrm{ISC}}$ for porphyrins and [8]circulenes, because the INDO calculations are not able to provide accurate electronic excitation energies for these molecules. A better accuracy has been obtained for porphyrins and [8]circulenes by combining the INDO method with excitation energies calculated at the timedependent density functional theory (TDDFT) and correlated $a b$ initio levels of theory. ${ }^{29-33}$ However, for some [8]circulenes the matrix elements of the nonadiabatic coupling (NACME) and the spin-orbit coupling (SOCME) operators calculated at the INDO level were found to be inaccurate. In this work, the electronic excitation energies, the coupling matrix elements, and the vibrational integrals are calculated at the density functional theory (DFT) and correlated $a b$ initio levels of theory, opening new possibilities of employing the theory of Plotnikov, Robinson, and Jortner without relying on any semiempirical parameters.

In this work we employ the theory of Plotnikov, Robinson, Jortner $^{24}$ using NACME and SOCME calculated at the DFT and $a b$ initio levels to obtain accurate values for the $k_{\mathrm{IC}}$ and $k_{\mathrm{ISC}}$ rate constants for nonradiative intramolecular transitions. The methods have been used in studies of pyrromethene-567 dye, psoralene, acenes, $f a c-\mathrm{Alq}_{3}, f a c$-Ir(ppy) $)_{3}$, hetero[8]circulenes, and free-base porphyrin, which are important in the different research areas of photonics. The reference values for the rate constants are also available for these molecules, ${ }^{34-40}$ since the photophysical properties of these compounds have previously been studied by other groups. ${ }^{29,31,33}$

\section{Theory}

\subsection{Non-radiative electronic transitions}

The general expression for the rate constant of non-radiative electronic transitions derived by Plotnikov, Robinson, Jortner reads $^{11,24}$

$$
k_{\mathrm{nr}}=\sum_{n}\left|V_{\mathrm{i} 0, \mathrm{f} n}\right|^{2} \Gamma_{\mathrm{f} n}\left[\Delta_{\mathrm{if}}^{2}+\frac{\Gamma_{\mathrm{f} n}^{2}}{4}\right]^{-1},
$$

where $\mathrm{i}$ is the initial electronic state, $\mathrm{f}$ is the final electronic state, $n$ is a vibrational level of $\mathrm{f}, \Gamma_{\mathrm{f} n}$ is the relaxation width of the vibronic level $|\mathrm{f} n\rangle, \Delta_{\mathrm{if}}=\left|E_{\mathrm{i} 0}-E_{\mathrm{f} n}\right|$ is the energy difference between the initial and final vibronic states, and $V_{\mathrm{i} o, \mathrm{f} n}$ is the matrix element of the perturbation operator. Only the lowest vibronic state is considered for the initial state. The perturbation operator is the spin-orbit coupling interaction for ISC transitions and the non-adiabatic coupling interaction for the IC process. eqn (1) written in atomic units holds at ambient temperatures $(T \leq 300 \mathrm{~K})$ when $k_{\mathrm{nr}} \ll \Gamma_{\mathrm{f} n}$. The conditions are generally fulfilled in experimental studies of luminescence properties. $\Gamma_{\mathrm{f} n}$ of about $10^{14} \mathrm{~s}^{-1}$ is generally much larger than the $k_{\mathrm{nr}}$ of about $10^{7}-10^{12} \mathrm{~s}^{-1} \cdot 24$ The $\Delta_{\text {if }}$ value is not larger than $100 \mathrm{~cm}^{-1}$ for polyatomic molecules. ${ }^{24}$ The expression can be simplified to eqn (2) when assuming that $\Gamma_{\mathrm{f} n}$ depends only weakly on the vibrational level $n$ and that $\Delta_{\text {if }} \ll \Gamma_{\mathrm{f} n}:^{24}$

$$
k_{\mathrm{nr}}=\frac{4}{\Gamma_{\mathrm{f}}} \sum_{n}\left|V_{\mathrm{i} 0, \mathrm{fn} n}\right|^{2}
$$

\subsection{IC rate constant}

In the framework of the adiabatic and Franck-Condon (FC) approximation, $V_{\mathrm{i} 0, \mathrm{f} n}$ can be written as ${ }^{24,41}$

$$
\begin{aligned}
V_{\mathrm{i} 0, \mathrm{f} n}= & \left\langle\mathrm{i}\left|T_{\mathrm{R}}\right| \mathrm{f}\right\rangle \cdot\langle 0 \mid n\rangle \\
& -\sum_{\nu} M_{\nu}^{-1}\left\langle 0\left|\frac{\partial}{\partial R_{\nu}}\right| \mathrm{n}\right\rangle \cdot\left\langle\mathrm{i}\left|\frac{\partial}{\partial R_{\nu}}\right| \mathrm{f}\right\rangle,
\end{aligned}
$$

where $T_{\mathrm{R}}$ is the kinetic energy operator of the electrons, $\nu$ is a nuclear index, $M_{\nu}$ is the mass of nucleus $\nu,\left\langle\mathrm{i}\left|\frac{\partial}{\partial R_{\nu}}\right| \mathrm{f}\right\rangle$ is the nonadiabatic coupling matrix element between the electronic states $|i\rangle$ and $|f\rangle,|0\rangle$ is the lowest vibration state of $|i\rangle$ and $|n\rangle$ is a vibration state of the final electronic state $|\mathrm{f}\rangle, R_{\nu}$ is the nuclear coordinates of nucleus $\nu$, and $\left\langle 0\left|\frac{\partial}{\partial R_{\nu}}\right| n\right\rangle$ is the nonadiabatic coupling matrix element between $|0\rangle$ and $|n\rangle$. The $\left\langle\mathrm{i}\left|\frac{\partial}{\partial R_{\nu}}\right| \mathrm{f}\right\rangle$ and $\left\langle 0\left|\frac{\partial}{\partial R_{\nu}}\right| n\right\rangle$ integrals are calculated for the equilibrium geometry $\left(R=R_{0}\right)$ of the $|\mathrm{f}\rangle$ state. Since the first term in eqn (3) 
is usually much smaller than the second term, eqn (3) can be written as $^{24,42}$

$$
V_{\mathrm{i} 0, \mathrm{f} n}=-\sum_{\nu} M_{\nu}^{-1}\left\langle 0\left|\frac{\partial}{\partial R_{\nu}}\right| n\right\rangle \cdot\left\langle\mathrm{i}\left|\frac{\partial}{\partial R_{\nu}}\right| \mathrm{f}\right\rangle,
$$

which can be expressed in Cartesian coordinates as

$$
V_{\mathrm{i} 0, \mathrm{f} n}=-\sum_{\nu} \sum_{q=x, y, z} M_{\nu}^{-1}\left\langle 0\left|\frac{\partial}{\partial R_{q v}}\right| n\right\rangle \cdot\left\langle\mathrm{i}\left|\frac{\partial}{\partial R_{q v}}\right| \mathrm{f}\right\rangle .
$$

$\left\langle 0\left|\frac{\partial}{\partial R_{q v}}\right| n\right\rangle$ can be written using normal coordinates when the rotational and translational motions have been identified and removed

$$
\left\langle 0\left|\frac{\partial}{\partial R_{q \nu}}\right| n\right\rangle=\left\langle 0_{1} 0_{2} \ldots 0_{3 N-6}\left|\sum_{j=1}^{3 N-6} B_{\nu q j} \frac{\partial}{\partial Q_{j}}\right| n_{1} n_{2} \ldots n_{3 N-6}\right\rangle,
$$

In eqn (6), $\left|0_{k}\right\rangle$ and $\left|n_{k}\right\rangle$ are the harmonic oscillator wave functions of the initial and final states, $n_{k}$ is the $n$th excitation of the $k$ th oscillator, $Q_{j}$ is the normal coordinate of the $j$ th oscillator, $B_{\nu q j}$ are matrix elements that describe the connection between the displacements in Cartesian coordinates of $\nu$ th atom $\left(\Delta R_{q \nu}\right)$ in respect to the equilibrium of and normal coordinate $\left(Q_{j}\right)$. By inserting eqn (6) into eqn (5) one obtains

$$
\begin{aligned}
V_{\mathrm{i} 0, \mathrm{f}\left\{n_{1} n_{2} \ldots n_{3 N-6}\right\}=} & \sum_{\nu} \sum_{q=x, y, z} M_{\nu}^{-1}\left\langle\mathrm{i}\left|\frac{\partial}{\partial R_{q \nu}}\right| \mathrm{f}\right\rangle \\
& \times\left[\sum_{j=1}^{3 N-6} B_{\nu q j}\left\langle 0_{j}\left|\frac{\partial}{\partial Q_{j}}\right| n_{j}\right\rangle \prod_{\substack{k \neq j \\
k=1}}^{3 N-6}\left\langle 0_{k} \mid n_{k}\right\rangle\right]
\end{aligned}
$$

$\left\langle 0_{j}\left|\frac{\partial}{\partial Q_{j}}\right| n_{j}\right\rangle$ can be expressed in harmonic approximation as

$$
\left\langle 0_{j}\left|\frac{\partial}{\partial Q_{j}}\right| n_{j}\right\rangle^{2}=\frac{1}{2 n_{j} !} \omega_{j}\left(n_{j}-y_{j}\right)^{2} y_{j}^{n_{j}-1} \cdot \exp \left(-y_{j}\right),
$$

where $y_{j}$ is the Huang-Rhys factor and $\omega_{j}$ is the vibration frequency of the $j$ th mode. The Franck-Condon factor $\left\langle 0_{k} \mid n_{k}\right\rangle$ can then be written as ${ }^{41}$

$$
\left\langle 0_{k} \mid n_{k}\right\rangle^{2}=\frac{\exp \left(-y_{k}\right) y_{k}^{n_{k}}}{n_{k} !} .
$$

The final expression is obtained by inserting eqn (8) and (9) into eqn (7):

$$
\begin{aligned}
V_{\mathrm{i} 0, \mathrm{f}\left\{n_{1} n_{2} . . n_{3 N-6}\right\}}= & -\sum_{\nu} \sum_{q=x, y, z} M_{\nu}^{-1}\left\langle\mathrm{i}\left|\frac{\partial}{\partial R_{q v}}\right| \mathrm{f}\right\rangle \\
& \times\left[\left(\prod_{k \neq j}^{3 N-6} \sqrt{\frac{\exp \left(-y_{k}\right) y_{k}^{n_{k}}}{n_{k} !}}\right)\right. \\
& \left.\times\left(\sum_{j=1}^{3 N-6} B_{v q j} \sqrt{\frac{1}{2 n_{j} !} \omega_{j}\left(n_{j}-y_{j}\right)^{2} \cdot y_{j}^{n_{j}-1} \exp \left(-y_{j}\right)}\right)\right] .
\end{aligned}
$$

The IC rate constant can be calculated using

$$
k_{\mathrm{IC}}=\frac{4}{\Gamma_{\mathrm{f}}} \sum_{n_{1}, n_{2} \ldots, n_{3 N-6}}^{E_{\mathrm{if}}=n_{1} \omega_{1}+n_{2} \omega_{2}+\ldots+n_{3 N-6} \omega_{3 N-6}}\left(V_{\mathrm{i} 0, \mathrm{f}\left\{n_{1} n_{2} . . n_{3 N-6}\right\}}\right)^{2},
$$

where the expression for $V_{\mathrm{i} 0, \mathrm{f}\left\{n_{1} n_{2} \ldots n_{3 N-6}\right\}}$ is given in eqn (10). $E_{\text {if }}$ is the energy gap between the electronic states $|\mathbf{i}\rangle$ and $|\mathbf{f}\rangle$.

\subsection{ISC rate constant}

The spin-orbit coupling is the perturbation operator of the ISC process. The spin-orbit coupling matrix elements depend only on the space and spin coordinates of the electrons but not on the nuclear ones. ${ }^{1,24}$ The expression for the ISC rate constant can then be written as

$$
\begin{aligned}
& k_{\mathrm{ISC}}=\frac{4}{\Gamma_{\mathrm{f}}} \sum_{n}\left\langle\mathrm{i}\left|H_{\mathrm{SO}}\right| \mathrm{f}\right\rangle^{2} \cdot\langle 0 \mid n\rangle^{2} \\
& =\frac{4}{\Gamma_{\mathrm{f}}}\left\langle\mathrm{i}\left|H_{\mathrm{SO}}\right| \mathrm{f}\right\rangle^{2}\left(\sum_{n_{1}, n_{2} . ., n_{3 N-6}}^{E_{\mathrm{if}}=n_{1} \omega_{1}+n_{2} \omega_{2}+\ldots+n_{3 N-6} \omega_{3 N-6}} \prod_{k=1}^{3 N-6} \sqrt{\frac{\exp \left(-y_{k}\right) y_{k}^{n_{k}}}{n_{k} !}}\right)^{2} .
\end{aligned}
$$

The excitations of the normal vibrations with the high frequency at $\omega=\sim 1000-1800 \mathrm{~cm}^{-1}$ and significant Huang-Rhys factor $(y>0.1)$ are the largest contributions to the summation $\left(E_{\text {if }}=n_{1} \omega_{1}+n_{2} \omega_{2}+\cdots+n_{3 N-6} \omega_{3 N-6}\right)$ in the expressions for the FC factor in eqn (11) and (12). ${ }^{6,12,24}$

\subsection{Parameters for the calculation of the ISC and IC rate constants}

To calculate the ISC and IC rate constants, values for $\left\langle\mathrm{i}\left|\frac{\partial}{\partial R_{q v}}\right| \mathrm{f}\right\rangle,\left\langle\mathrm{i}\left|H_{\mathrm{SO}}\right| \mathrm{f}\right\rangle, y_{j}$ and $\omega_{j}, E_{\text {if }}$ and $\Gamma_{\mathrm{f}}$ are needed. In this work, $\left\langle\mathrm{i}\left|\frac{\partial}{\partial R_{q v}}\right| \mathrm{f}\right\rangle$ is calculated for molecules consisting of more than 50 atoms at the TDDFT level using Turbomole ${ }^{42}$ and for smaller molecules they are calculated at the CASSCF level of theory in GAMESS-US. ${ }^{43}$ The Huang-Rhys factors and the vibration frequencies $\left(\omega_{j}\right)$ are calculated at the DFT and correlated $a b$ initio levels of theory. ${ }^{44}$ The $\left\langle\mathrm{i}\left|H_{\text {So }}\right| \mathrm{f}\right\rangle$ matrix elements have been computed at the CASSCF and TDDFT levels. ${ }^{45,46}$ The line width $\left(\Gamma_{\mathrm{f}}\right)$ has been estimated using the Lax and Pekar models ${ }^{47-49}$ in the simulation of molecular vibronic spectra using the displaced oscillator model.

\section{Computational methods and studies}

\subsection{Studied molecules}

The computational methods described above have been employed on a number of molecules with interesting photophysical properties. The studied molecules shown in Fig. 1 comprise the commercial laser dye 1,3,5,7,8-pentamethyl-2,6-diethylpyrromethene-difluoroborate (PM567), ${ }^{34} 7 \mathrm{H}$-furo[3,2-g]chromen-7-one (psoralene), ${ }^{35}$

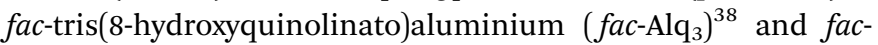
tris(2-phenylpyridine)iridium ( $f a c$ - $\left.\operatorname{Ir}(\mathrm{ppy})_{3}\right){ }^{39}$ tetraoxa[8]circulene $(4 \mathrm{~B})^{36}$ and its $\mathrm{NH}$ substituted and benzoannelated derivatives 


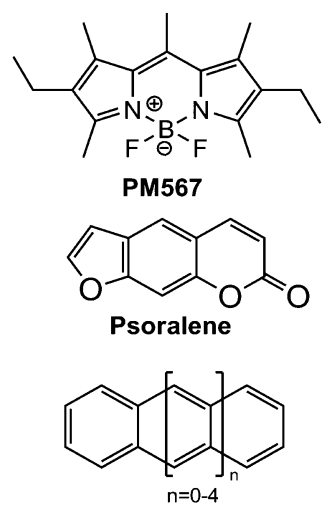

Polyacenes

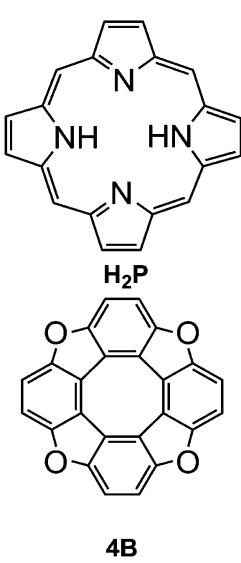

$4 B$

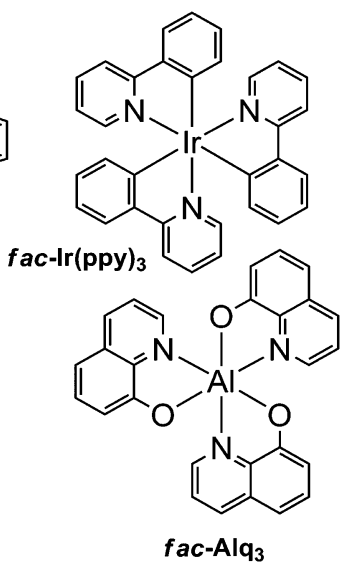

fac-Alq 3

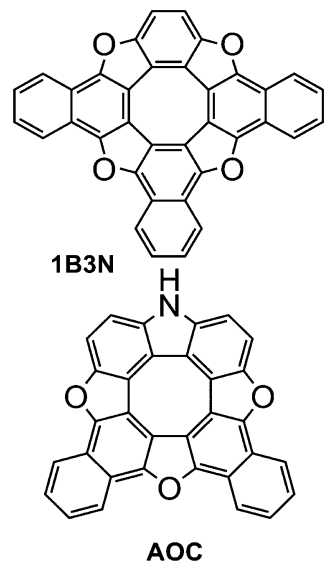

Fig. 1 The molecular structures of the studied molecules.

(AOC) and $(1 \mathrm{~B} 3 \mathrm{~N}),{ }^{29}$ polyacenes (naphthalene, anthracene, tetracene, pentacene, and hexacene), ${ }^{37}$ and free-base porphyrin $\left(\mathrm{H}_{2} \mathrm{P}\right) .{ }^{42}$

The molecules were chosen for the following reasons. PM567 has a very large fluorescence quantum yield of $\varphi_{\mathrm{fl}}=0.9-1.0$ and is therefore often used in laser devices. ${ }^{38}$ Psoralene has a very small fluorescence quantum yield of $\varphi_{\mathrm{fl}} \sim 0.1$ and a large $k_{\mathrm{ISC}}{ }^{37}$ and is therefore used in photodynamic therapy applications. ${ }^{37} \mathrm{Alq}_{3}$ and $\operatorname{Ir}(\text { ppy })_{3}$ are used in OLED devices. ${ }^{38,39}$ The electroluminescence of $\mathrm{Alq}_{3}$ and $\operatorname{Ir}(\mathrm{ppy})_{3}$ is due to fluorescence and phosphorescence, respectively. ${ }^{38,39}$ The photophysical properties of [8]circulenes have previously been studied by us at the INDO level of theory using the method of Plotnikov, Robinson, Jortner. ${ }^{29}$

The chosen compounds have very different fluorescence quantum yields $\varphi_{\mathrm{fl}}$. The fluorescence spectrum of the polyacenes has a complicated vibronic fine structure requiring calculations of transition moments between many excited states with different spins. ${ }^{50}$ The energy gap between the first excited singlet state $\left(\mathrm{S}_{1}\right)$ and the ground state $\left(\mathrm{S}_{0}\right)$ systematically reduces from the ultraviolet to infrared spectral region when increasing the number of benzoic rings in the polyacene..$^{50}$ The calculations on the polyacenes yield a relation between $k_{\mathrm{IC}}$ and the optical gap. The present approach is also applied to free-base porphyrin $\left(\mathrm{H}_{2} \mathrm{P}\right)$, because it is well known that the calculation of $k_{\mathrm{IC}}$ and $k_{\mathrm{ISC}}$ for $\mathrm{H}_{2} \mathrm{P}$ is challenging. ${ }^{1}$

\subsection{Computational methods}

The molecular structures of the ground electronic states $\left(\mathrm{S}_{0}\right)$ of all the molecules except $\mathrm{Alq}_{3}$ and $\operatorname{Ir}(\mathrm{ppy})_{3}$ were optimized at the density functional theory (DFT) level ${ }^{51}$ using the B3LYP ${ }^{52}$ exchange-correlation functional and def2-TZVP ${ }^{53}$ basis sets. For $\mathrm{Alq}_{3}$ and $\operatorname{Ir}(\mathrm{ppy})_{3}$, the $\omega \mathrm{B} 97 \mathrm{xD}$ functional was employed in the DFT optimization of the molecular structures. ${ }^{54}$ The def2-TZVP basis sets were used for $\mathrm{Alq}_{3}$. For Ir(ppy) $)_{3}$, we used the LANL2DZ basis set and effective core potentials for Ir and the $6-31 \mathrm{G}(\mathrm{d}, \mathrm{p})$ basis sets for the rest of the atoms. ${ }^{55}$ The equilibrium geometry of the first excited electronic state $\left(\mathrm{S}_{1}\right)$ was obtained at the TDDFT/B3LYP/def2-TZVP level of theory for PM567, psoralene, polyacenes, and free-base porphyrin. The molecular structures of the first excited state $\left(\mathrm{S}_{1}\right)$ of $\mathrm{Alq}_{3}$ and $\operatorname{Ir}(\mathrm{ppy})_{3}$ were optimized at the TDDFT level using the $\omega \mathrm{B} 97 \mathrm{xD}$ functional. ${ }^{54}$
We chose the $\omega \mathrm{B} 97 \mathrm{xD}$ functional for $\mathrm{Alq}_{3}$ and $\operatorname{Ir}(\mathrm{ppy})_{3}$, because difficulties arise when using the B3LYP functional to properly describe excited states of metal-ligand compounds with significant charge-transfer characteristics, whereas the $\omega \mathrm{B} 97 \mathrm{xD}$ functional is expected to be able to describe such states better, since it has the correct long-range shape of the potential. ${ }^{39}$ The molecular structure optimizations were carried out using Gaussian-09 software. ${ }^{56}$ Only the lowest isomers of fac-Alq $_{3}$ and fac-Ir(ppy $)_{3}$ were considered.

Calculations of singlet and triplet excitation energies were carried out using the extended multi-configuration quasidegenerate perturbation theory at the second order (XMCQDPT2), ${ }^{57}$ because this level of theory has been found to yield the correct relative order of the lowest singlet and triplet electronic states for organic and organometallic compounds. ${ }^{58}$ The XMCQDPT2 calculations were performed using the optimized molecular structures of the $\mathrm{S}_{1}$ state. In the XMC-QDPT2 calculations, 30 states were included in the effective Hamiltonian. The number of active electrons (e), number of active orbitals (o), and the number of states (s) of the state-average (SA) complete active self-consistent space field (CASSCF) calculations are PM567 ( 8 e, 6 o, $5 \mathrm{~s}$ ), psoralene (10 e, 9 o, 5 s), Alq 3 (12 e, 9 o, $5 \mathrm{~s})$, $\operatorname{Ir}(\text { ppy })_{3}(12 \mathrm{e}, 9 \mathrm{o}, 5 \mathrm{~s})$, tetraoxa[8]circulene (4B) $(10 \mathrm{e}, 10 \mathrm{o}, 10 \mathrm{~s})$, $o$-dinaphthalene-containing azatrioxa[8]circulene (AOC) $(10 \mathrm{e}$, $10 \mathrm{o}, 10 \mathrm{~s})$, trinaphthalene-containing tetraoxa[8]circulene (1B3N), $(10 \mathrm{e}, 11 \mathrm{o}, 10 \mathrm{~s})$, free-base porphyrin $\left(\mathrm{H}_{2} \mathrm{P}\right)(11 \mathrm{e}, 14 \mathrm{o}, 10 \mathrm{~s})$, naphthalene (12 e, $9 \mathrm{o}, 10 \mathrm{~s})$, anthracene (10 e, $10 \mathrm{o}, 10 \mathrm{~s})$, tetracene $(10$ e $11 \mathrm{o}, 10 \mathrm{~s})$, pentacene $(8 \mathrm{e}, 8 \mathrm{o}, 10 \mathrm{~s})$, and hexacene ( 8 e, 8 o, 10 s). The XMC-QDPT2 calculations were carried out using Firefly. ${ }^{59}$

The discrepancy between the TDDFT and XMC-QDPT2 excitation energies for the $S_{1} \rightarrow S_{0}$ electronic transitions does not exceed $1000-1500 \mathrm{~cm}^{-1}$ for any of the studied compounds. Thus, a combination of the XMC-QDPT2 and TDDFT levels of theory can be used in the calculation of photophysical properties.

\subsection{Huang-Rhys factors and vibrational relaxation widths}

The $y_{j}, \omega_{j}$, and $\Gamma_{\mathrm{f}}$ values were obtained using the Lax and Pekar model, ${ }^{47-49}$ which is described in detail in ref. 48 and 49. 
The potential energy surfaces of $S_{0}$ and $S_{1}$ are assumed to be harmonic with the same vibrational energies $\left(\omega_{j}\right)$ for the two states. The energy functions for the two states can then be written as

$$
\begin{aligned}
& E^{\mathrm{i}}(Q)=E^{\mathrm{i}}\left(Q^{0}\right)+\sum_{j} V_{j}^{\mathrm{i}}\left(Q_{j}-Q_{j}^{0}\right)+\frac{1}{2} \sum_{j} \omega_{j}^{2}\left(Q_{j}-Q_{j}^{0}\right)^{2}, \\
& E^{\mathrm{f}}(Q)=E^{\mathrm{f}}\left(Q^{0}\right)+\sum_{j} V_{j}^{\mathrm{f}}\left(Q_{j}-Q_{j}^{0}\right)+\frac{1}{2} \sum_{j} \omega_{j}^{2}\left(Q_{j}-Q_{j}^{0}\right)^{2}
\end{aligned}
$$

where $\{Q\}$ is the set of normal coordinates of the harmonic oscillators, $V_{j}^{\mathrm{i}, \mathrm{f}}=\partial E^{\mathrm{i}, \mathrm{f}} /\left.\partial Q\right|_{Q=Q_{0}}$ is the gradient of the potential energy surface along the $j$ th mode at a chosen point $Q^{0}$. From eqn (13) it is easily seen that

$$
\begin{aligned}
& \frac{\partial E^{\mathrm{i}, \mathrm{f}}(Q)}{\partial Q_{j}}=V_{j}^{\mathrm{i}, \mathrm{f}}+\omega_{j}^{2}\left(Q_{j}-Q_{j}^{0}\right) \\
& \frac{\partial E^{\mathrm{f}}(Q)}{\partial Q_{j}}-\frac{\partial E^{\mathrm{i}}(Q)}{\partial Q_{j}}=V_{j}^{\mathrm{f}}-V_{j}^{\mathrm{i}}=\mathrm{const} \\
& Q_{j}^{\mathrm{i}, \mathrm{f}}-Q_{j}^{0}=-\frac{V_{j}^{\mathrm{i}, \mathrm{f}}}{\omega_{j}^{2}} .
\end{aligned}
$$

Thus, $\Delta Q_{j}=-\left(V_{j}^{\mathrm{f}}-V_{j}^{\mathrm{i}}\right) / \omega_{j}^{2}$ and finally the Huang-Rhys factors $\left(y_{j}\right)$ are obtained as

$$
y_{j}=\frac{1}{2} \omega_{j} \Delta Q_{j}^{2}=\frac{\left(V_{j}^{\mathrm{f}}-V_{j}^{\mathrm{i}}\right)^{2}}{2 \omega_{j}^{3}} .
$$

The line width $\Gamma_{\mathrm{f}}$ is taken from the generation function for the simulation of the profile of the vibration spectra within the Lax-Pekar model. ${ }^{47-49}$ The calculated value for $\Gamma_{\mathrm{f}}$ is about $1.6 \times 10^{14} \mathrm{~s}^{-1}$ for the $S_{1}$ state of the studied molecules.

The optimized molecular structures of the $S_{0}$ and $S_{1}$ states as well as the gradient and the Hessian calculated for the $S_{0}$ state were used in the calculation of $\omega_{j}$ and $V_{j}^{\mathrm{i}, \mathrm{f}}$. In the calculation of the IC rate constants, the Hessian was calculated for the $S_{0}$ state, whereas the gradient for the $S_{1}$ state was calculated using the molecular structure of the $S_{0}$ state. We assume that the vibrational energies $\left(\omega_{j}\right)$ and the Huang-Rhys factors $y_{i}$ are the same for the IC and ISC processes. Our previous calculations showed that this assumption yields good estimates for the ISC rate constants for several molecules. ${ }^{29,58}$

\subsection{Calculation of matrix elements}

The nonadiabatic coupling matrix elements $\left\langle\mathrm{S}_{0}\left|\frac{\partial}{\partial R_{q v}}\right| \mathrm{S}_{1}\right\rangle$ were calculated with Turbomole at the TDDFT level of theory using the perturbation theory. ${ }^{42,60}$ The spin-orbit coupling matrix elements $\left\langle\mathrm{S}_{1}\left|H_{\mathrm{SO}}\right| T_{i}\right\rangle$ between the $\mathrm{S}_{1}$ state and the energetically lower $i$ th triplet state $T_{i}$ were calculated at the CASSCF level using Gamess-US. ${ }^{61}$ The excitation energies calculated at the XMCQDPT2 level were used as the zeroth-order values. In order to calculate $k_{\mathrm{ISC}}$, the one-electron spin-orbit coupling operator of the Pauli-Breit Hamiltonian was used. ${ }^{62}$ The contributions from the two-electron part of the spin-orbit coupling operator are beyond the Franck-Condon approximation. ${ }^{1}$ However, previous calculations have shown that the use of the one-electron spinorbit operator within the FC approximation leads to accurate $k_{\text {ISC }}$ values for the organic and organometallic compounds. ${ }^{29,58,63}$

\subsection{Radiative rate constants and fluorescence quantum yields}

When contributions from higher excited states can be neglected, the fluorescence quantum yield from the $S_{1}$ state can be obtained as ${ }^{9,12}$

$$
\varphi_{\mathrm{fl}}=\frac{k_{\mathrm{r}}}{k_{\mathrm{r}}+k_{\mathrm{IC}}+\sum_{i} k_{\mathrm{IST}_{i}}}
$$

where $k_{\mathrm{IST}_{i}}$ is a ISC rate constant between $\mathrm{S}_{1}$ and energetically lower triplet states $T_{i}, k_{\mathrm{r}}$ and $k_{\mathrm{IC}}$ are the radiative and IC rate constants of the electronic transition from $S_{1}$ to $S_{0}$, respectively. The $k_{\mathrm{r}}$ can be estimated using the Strickler-Berg equation ${ }^{64}$

$$
k_{\mathrm{r}}=\frac{1}{1.5} \cdot f \cdot E^{2}\left(\mathrm{~S}_{1} \rightarrow \mathrm{S}_{0}\right),
$$

where $f$ is the oscillator strength and $E\left(\mathrm{~S}_{1} \rightarrow \mathrm{S}_{0}\right)$ is the de-excitation energy from $S_{1}$ to $S_{0}$.

The table illustrating the employed level of theory is given for

\begin{tabular}{|c|c|c|c|}
\hline Geometries of $S_{0}$ and $S_{1}$ states & DFT/B3LYP/def2-TZVP & 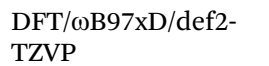 & $\begin{array}{l}\text { DFT/ } \omega \text { B } 97 x D / L A N L 2 D Z \text { and } 6- \\
31 G(d, p)\end{array}$ \\
\hline $\begin{array}{l}\text { Energies of } \mathrm{S}_{1} \rightarrow \mathrm{S}_{0} \text { electronic transition and triplet } \\
\text { states, oscillator strength }(f)\end{array}$ & XMC-QDPT2/def2-TZVP & $\begin{array}{l}\text { XMC-QDPT2/ } \\
\omega B 97 x D / \text { def2-TZVP }\end{array}$ & $\begin{array}{l}\text { XMC-QDPT2/ } / \omega \mathrm{B} 97 \mathrm{xD} / \\
\text { LANL2DZ and 6-31G(d,p) }\end{array}$ \\
\hline$\left\langle\mathrm{S}_{0}\left|\frac{\partial}{\partial R_{q v}}\right| \mathrm{S}_{1}\right\rangle$ & TD-DFT/B3LYP/def2-TZVP & $\begin{array}{l}\text { TDDFT/B3LYP/def2- } \\
\text { TZVP }\end{array}$ & TDDFT/B3LYP/def2-TZVP \\
\hline$y, \omega$ and $\Gamma$ & (TD)-DFT/B3LYP/def2-TZVP & $\begin{array}{l}\text { (TD)-DFT/ } \omega \mathrm{B} 97 \mathrm{xD} / \\
\text { def2-TZVP }\end{array}$ & $\begin{array}{l}\text { (TD)-DFT/ } \omega \text { B97xD/LANL2DZ } \\
\text { and } 6-31 \mathrm{G}(\mathrm{d}, \mathrm{p})\end{array}$ \\
\hline
\end{tabular}
clear understanding of the subsequent discussions (Table 1).

\section{Results and discussion}

\section{1. $\quad$ Pm567}

The optimized molecular structure of the $S_{1}$ state is shown in Fig. 2a. The energy levels of the lowest singlet and triplet states and the $k_{\mathrm{IC}}$ and $k_{\mathrm{ISC}}$ rate constants of the transitions are shown

Table 1 The employed levels of theory for the compounds under investigation 


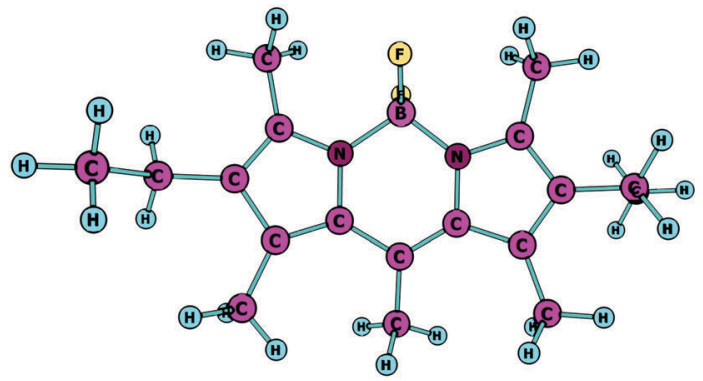

(a)

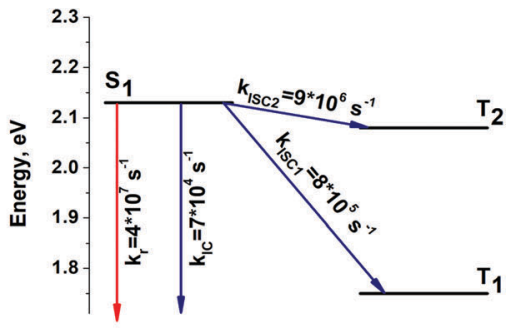

(b)

Fig. 2 (a) The optimized molecular structure of PM567. (b) The energy level diagram for PM567 including the computed values for the radiative and nonradiative rate constants.

Table 2 The calculated excitation energies (in eV) of the studied molecules are compared to available experimental data. Calculated oscillator strengths are given in parenthesis

\begin{tabular}{|c|c|c|c|}
\hline Compound & State & XMC-QDPT2 & Exp. \\
\hline \multirow[t]{3}{*}{ PM567 } & $\mathrm{S}_{1}$ & $2.13(0.2)$ & $2.22^{a}$ \\
\hline & $\mathrm{T}_{1}$ & 1.75 & - \\
\hline & $\mathrm{T}_{2}$ & 2.08 & - \\
\hline \multirow[t]{3}{*}{ Psoralene } & $\mathrm{S}_{1}$ & $3.09(0.2)$ & $3.02^{b}$ \\
\hline & $\mathrm{T}_{1}$ & 2.75 & $2.73^{b}$ \\
\hline & $\mathrm{T}_{2}$ & 3.02 & - \\
\hline \multirow[t]{3}{*}{ 4B } & $\mathrm{S}_{1}$ & 2.64 & $2.44^{c}$ \\
\hline & $\mathrm{T}_{1}$ & 1.89 & \\
\hline & $\mathrm{T}_{2}\left(\mathrm{~T}_{3}\right)$ & 2.58 & \\
\hline \multirow[t]{3}{*}{$\mathrm{AOC}$} & $\mathrm{S}_{1}$ & $3.00(0.3)$ & $3.02^{c}$ \\
\hline & $\mathrm{T}_{1}$ & 1.89 & \\
\hline & $\mathrm{T}_{2}$ & 2.9 & \\
\hline \multirow[t]{5}{*}{$1 \mathrm{~B} 3 \mathrm{~N}$} & $\mathrm{~S}_{1}$ & $2.68(0.5)$ & $3.08^{c}$ \\
\hline & $\mathrm{T}_{1}$ & 2.1 & \\
\hline & $\mathrm{T}_{2}$ & 2.24 & \\
\hline & $\mathrm{T}_{3}$ & 2.34 & \\
\hline & $\mathrm{T}_{4}$ & 2.64 & \\
\hline \multirow[t]{3}{*}{$\mathrm{H}_{2} \mathrm{P}$} & $\mathrm{S}_{1}$ & 1.92 & $2.01^{d}$ \\
\hline & $\mathrm{T}_{1}$ & 1.62 & $1.58^{d}$ \\
\hline & $\mathrm{T}_{2}$ & 1.8 & \\
\hline \multirow[t]{2}{*}{$\mathrm{Alq}_{3}$} & $\mathrm{~S}_{1}$ & $2.33(0.1)$ & $2.38-2.48^{e}$ \\
\hline & $\mathrm{T}_{1}$ & 1.86 & - \\
\hline \multirow[t]{2}{*}{$\operatorname{Ir}(\text { ppy })_{3}$} & $\mathrm{~S}_{1}$ & 2.74 & $2.69^{f}$ \\
\hline & $\mathrm{T}_{1}$ & 2.37 & $2.44^{f}$ \\
\hline
\end{tabular}

${ }^{a}$ Ref. $38 .{ }^{b}$ Ref. $37 .{ }^{c}$ Ref. $29{ }^{d}$ Ref. $40{ }^{e}$ Ref. $34 .{ }^{f}$ Ref. 35.

in Fig. $2 b$. Table 2 contains the calculated excitation energy of the $\mathrm{S}_{1}$ state and the excitation energies calculated for the triplet states that are energetically below $\mathrm{S}_{1}$. The calculated excitation energy for $S_{1}$ agrees well with the experimental value with a deviation of only $0.09 \mathrm{eV}$. The rate constants in Fig. $2 \mathrm{~b}$ show that $k_{\mathrm{r}}$ is a main deactivation channel of the $\mathrm{S}_{1}$ state. The largest rate constant among the nonradiative transitions is $k_{\mathrm{ISC} 2}$ due to the small energy gap between $S_{1}$ and $T_{2}$. The calculated fluorescence quantum yield $(\varphi)$ is 0.79 , which qualitatively agrees with the experimental one of $0.9 .^{38}$ Thus, the present approach is able to predict the large $\left(\varphi_{\mathrm{fl}}\right)$ observed for PM567. The largest values for the Huang-Rhys factors $\left(y_{j}\right)$ and corresponding wavenumbers $\left(\omega_{j}\right)$ are given in Table 3 . The vibrational mode at $1255 \mathrm{~cm}^{-1}$ has a large $y$ value of 0.1 . Since only one vibrational mode has a large $y$ value in that energy range the nonradiative rate constants $k_{\mathrm{IC}}$ and $k_{\mathrm{ISC}}$ are small as compared with the rate constant of the radiative transition $k_{\mathrm{r}}$.

\subsection{Psoralene}

The optimized molecular structure of the $\mathrm{S}_{1}$ state of psoralene is shown in Fig. 3a. The energies of the lowest singlet and triplet states and the $k_{\mathrm{IC}}$ and $k_{\mathrm{ISC}}$ rate constants are shown in Fig. $3 \mathrm{~b}$. The excitation energies listed in Table 2 agree well with the experimental values. The dominating deactivated channel of the $\mathrm{S}_{1}$ state is via the $k_{\mathrm{ISC} 1}$ channel, because of the strong spin-orbit coupling interaction between $S_{1}$ and $T_{1}$. See Table $S 1$ in the ESI. $\dagger$ The calculated and experimental quantum yields of 0.08 are in perfect agreement. ${ }^{35}$ The calculated excitation energies were found to agree very well with the experimental ones, even though the solvent effect can be as large as $1 \%$ for psoralene. ${ }^{35}$ The calculated $y_{j}$ and $\omega_{j}$ values for psoralene are given in Table 3, where one sees that many vibrational modes with energies larger than $1000 \mathrm{~cm}^{-1}$ have large $y_{j}$ values leading to a high density of FC factors and fast nonradiative transitions. The calculated rate constants explain the low value and the high triplet quantum yield of psoralene.

\section{3. [8]circulenes $4 \mathrm{~B}, \mathrm{AOC}$ and $1 \mathrm{~B} 3 \mathrm{~N}$}

The optimized molecular structures of the $S_{1}$ state of tetraoxa[8]circulene (4B) and its $\mathrm{NH}$ substituted and benzoannelated derivatives (AOC) and (1B3N) are shown in Fig. 3a, c, and e. The energy levels of their lowest singlet and triplet states and the $k_{\mathrm{IC}}$ and $k_{\text {ISC }}$ rate constants are shown in Fig. $3 \mathrm{~b}, \mathrm{~d}$ and f, respectively. The lowest excitation energies are given in Table 2. The intensity for the radiative $\mathrm{S}_{0}-\mathrm{S}_{1}$ transition for tetraoxa[8]circulene (4B) vanishes in the $\mathrm{FC}$ approximation. The transition becomes allowed in the Herzberg-Teller approximation. ${ }^{65}$ An oscillator strength for $4 \mathrm{~B}$ of 0.03 is obtained from the experimental extinction coefficient $f=4.32 \times 10^{-9} \int \varepsilon(v) \mathrm{d} v{ }^{66}$ The spin-orbit 
Table 3 Calculated wavenumbers $\omega_{j}$ (in $\mathrm{cm}^{-1}$ ) for a few relevant vibrational modes. The largest Huang-Rhys factors $\left(y_{j}\right)$ for the $S_{1} \rightarrow S_{0}$ and $S_{1} \rightarrow T_{j}$ nonradiative transitions are given in parenthesis

\begin{tabular}{ll}
\hline Compound & $\omega_{j}\left(y_{j}\right)$ \\
\hline PM567 & $210(0.05) ; 571(0.12) ; 1255(0.1)$ \\
Psoralene & $234(0.29) ; 396(0.65) ; 742(0.42) ; 1103(0.15) ; 1164(0.25) ; 1190(0.54) ; 1615(0.14) ; 1689(0.24) ; 1877(0.08)$ \\
4B & $662(0.17) ; 1051(0.07) ; 1276(0.35) ; 1453(0.19) ; 1536(0.16) ; 1703(0.84)$ \\
AOC & $1308(0.05) ; 1473(0.14) ; 1675(0.15) ; 1678(0.05)$ \\
1B3N & $232(0.05) ; 1474(0.15) ; 1518(0.05) ; 1687(0.05)$ \\
$\mathrm{H}_{2} \mathrm{P}$ & $157(0.05) ; 310(0.14) ; 1393(0.03)$ \\
Alq $_{3}$ & $141(0.36) ; 151(0.25) ; 164(0.08) ; 185(0.08) ; 213(0.06) ; 357(0.54) ; 422(0.09) ; 458(0.10) ; 506(0.12) ; 554(0.34) ;$ \\
$\operatorname{Ir}_{(\text {ppy })_{3}}$ & $585(0.11) ; 587(0.13) ; 661(0.33) ; 670(0.21) ; 1434(0.1) 1634(0.07) ; 1637(0.29) ; 1659(0.07)$ \\
& $121(0.28) ; 146(0.46) ; 187(0.08) ; 258(0.31) ; 269(0.06) ; 1040(0.01) ; 1512(0.14) ; 1615(0.11)$
\end{tabular}

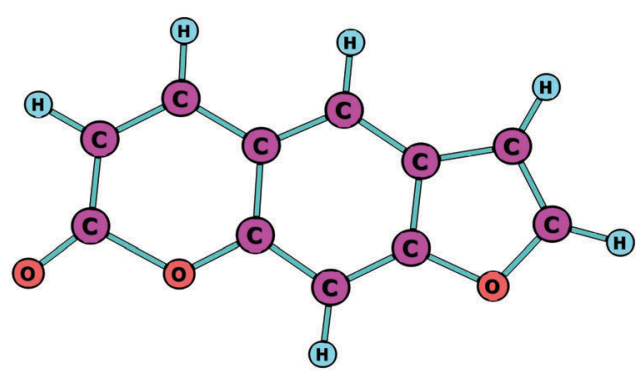

(a)

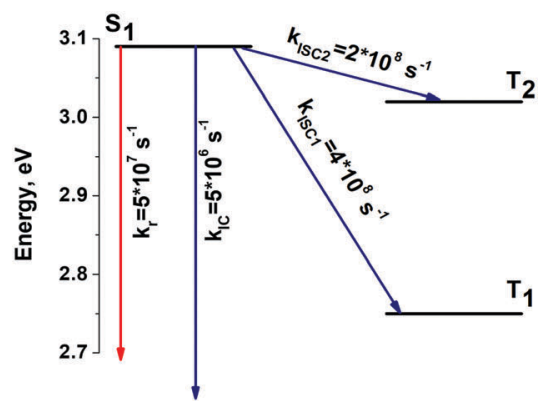

(b)

Fig. 3 (a) The optimized molecular structure of psoralene. (b) The energy level diagram for psoralene including the computed values for the radiative and nonradiative rate constants.

coupling matrix elements between $\mathrm{S}_{1}$ and $\mathrm{T}_{j}$ vanish due to symmetry reasons since the molecule belongs to the $D_{4 \mathrm{~h}}$ point group. Thus, IC is the main deactivation channel of the $S_{1}$ state. The calculated value for $\varphi_{\mathrm{fl}}$ is 0.13 , which agrees well with the experimental value of $0.09 .^{36}$ AOC has the largest quantum yield $\left(\varphi_{\mathrm{fl}}\right)$ of about 1.0 , because the rate constant $k_{\mathrm{ISC}}$ is close to zero and $k_{\mathrm{IC}}$ is significantly smaller than $k_{\mathrm{r}}$. The experimental $\varphi_{\mathrm{fl}}$ value for AOC is $0.91 .{ }^{29} 1 \mathrm{~B} 3 \mathrm{~N}$ has a smaller calculated $\varphi_{\mathrm{fl}}$ of 0.56 which is in reasonable agreement with the experimental value of $0.36 .{ }^{29}$ The reason for the smaller $\varphi_{\mathrm{fl}}$ value is the presence of several low-lying triplet states. The main deactivation channel of the $S_{1}$ state is then the ISC process. The present calculations explain why the studied [8]circulenes have different quantum yields. The largest $y_{j}$ values and the corresponding vibrational energies $\left(\omega_{j}\right)$ are listed in Table 3 . The main vibrational mode for the nonradiative transition is at about $1400 \mathrm{~cm}^{-1}$ for AOC and 1B3N. We have previously calculated $k_{\text {IC }}$ and $k_{\text {ISC }}$ at the INDO level of theory using one vibrational mode with an energy of $1400 \mathrm{~cm}^{-1} .^{29}$ The obtained results were in good agreement with the present ones except for $k_{\mathrm{IC}}$ of tetraoxa[8]circulenes (4B), because the NACMEs calculated at the INDO level are inaccurate. The reason for the deviation can be traced back to the large $y_{j}$ factor for the vibrational mode at $1703 \mathrm{~cm}^{-1}$, which consists of vibrational motion inside the macrocycle. ${ }^{65}$ For the other [8] circulenes (AOC and 1B3N), this mode has a smaller $y_{j}$ value. The present calculations show that the INDO approach does not yield accurate nonradiative rate constants for tetraoxa[8]circulene (4B) (Fig. 4).

\subsection{Free-base porphyrin}

Calculation of the nonradiative rate constants $k_{\text {IC }}$ and $k_{\text {ISC }}$ for $\mathrm{H}_{2} \mathrm{P}$ is a challenge. ${ }^{1}$ Several previous works have shown that the FC approximation is not enough to obtain accurate rate constants. ${ }^{1,15}$ The intensity of the $\mathrm{Q}$ band in the electronic absorption spectrum for $\mathrm{H}_{2} \mathrm{P}$ can be accurately simulated only when considering vibrational effects at the Herzberg-Teller approximation. ${ }^{67}$ In this work, we adopted the experimental value 0.03 for the oscillator strength $(f)$ in the calculation of $k_{\mathrm{r}}$ using eqn (17). The molecular structure of free-base porphyrin is shown in Fig. 5a and the calculated energy levels and rate constants are presented in Fig. 5b. The calculated rate constants for the nonradiative transitions $k_{\mathrm{IC}}$ and $k_{\mathrm{ISC}}$ are underestimated, because the present calculations yield a quantum yield of 0.96 , which is an order of magnitude larger than the experimental value of $0.08 .{ }^{40} \mathrm{~A}$ previously calculated value for $k_{\mathrm{ISC} 1}$ is $\sim 10^{7} \mathrm{~s}^{-1} \cdot{ }^{15}$ The largest Huang-Rhys factors $\left(y_{j}\right)$ and the corresponding vibrational frequencies are listed in Table 3 . The calculated $y_{j}$ values are very small leading to an underestimation of the rate constants of the nonradiative transitions. The vibrational modes with energies in the range $1000 \mathrm{~cm}^{-1}<\omega_{j}<3000 \mathrm{~cm}^{-1}$ contribute significantly to the FC factor. The $y_{j}$ values of the vibrational modes in this energy range should be about $0.1-0.4$. However, the largest $y_{j}$ value is 0.03 for the vibrational mode at $1393 \mathrm{~cm}^{-1}$, which is about one order of magnitude too small. In our previous INDO study considering one vibrational mode at $1400 \mathrm{~cm}^{-1}$, an empirical $y_{j}$ value of 0.3 was used leading to the rather accurate values for $k_{\mathrm{IC}}$ and $k_{\mathrm{ISC}}{ }^{33}$ Thus, one has to go beyond the FC 


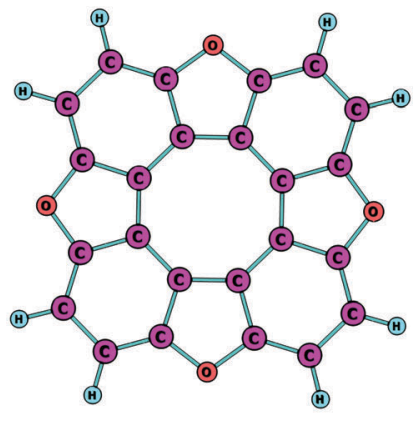

(a)

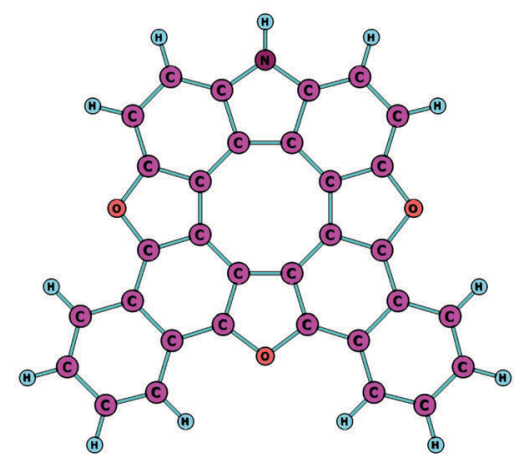

(c)

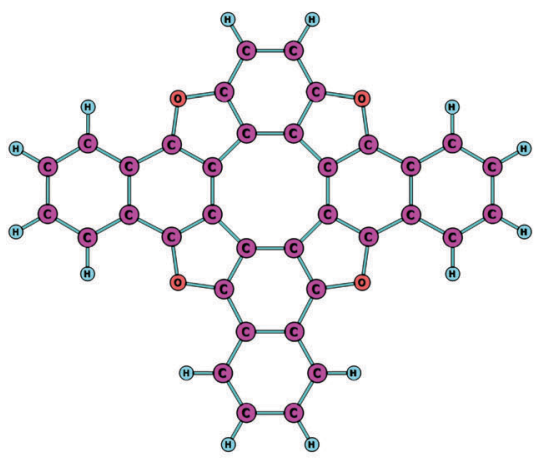

(e)

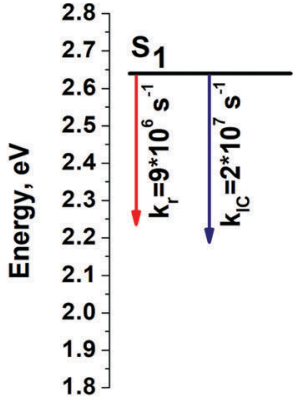

(b)

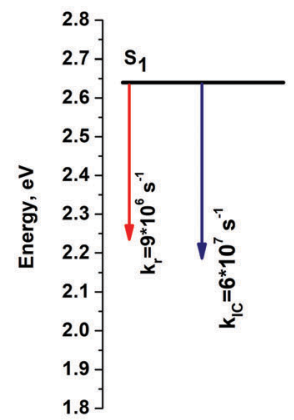

(d)

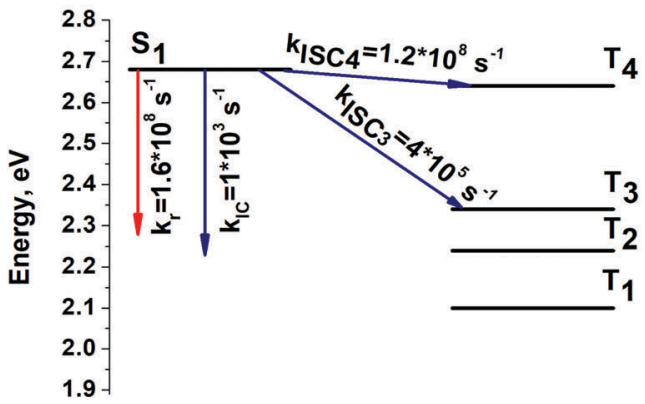

$(f)$

Fig. 4 The optimized molecular structures of (a) 4B, (c) AOC and (e) 1B3N. The energy levels and rate constants are given for the same molecules in (b), (d), and (f), respectively.

approximation in order to obtain accurate values for the nonradiative rate constants of free-base porphyrin.

\section{5. $\mathrm{Alq}_{3}$ and $\operatorname{Ir}(\mathrm{ppy})_{3}$}

The optimized molecular structures of the $S_{1}$ state of $f a c$-tris(8hydroxyquinolinato)aluminium ( $\left.f a c-\mathrm{Alq}_{3}\right)$ and $f a c$-tris(2-phenylpyridine)iridium $\left(\right.$ fac- $\left.\operatorname{Ir}(\mathrm{ppy})_{3}\right)$ are shown in Fig. $6 \mathrm{a}$ and $\mathrm{c}$. The energy levels of the lowest singlet and triplet states and the $k_{\text {IC }}$ and $k_{\text {ISC }}$ rate constants of the transitions are shown in Fig. $6 \mathrm{~b}$ and $d$. The calculated excitation energies of the $S_{1}$ and
$\mathrm{T}_{1}$ states are compared with the experimental data in Table 2. The calculated excitation energies agree well with the experimental data. Only the lowest triplet state lies below the $S_{1}$ state. For $\mathrm{Alq}_{3}$, the radiative and the two nonradiative deactivation channels of the $S_{1}$ state have almost the same rate constants. The calculated quantum yield $\left(\varphi_{\mathrm{fl}}\right)$ of 0.25 agrees with the experimental values of 0.04-0.3 that strongly depend on environmental effects. ${ }^{38}$ For $\operatorname{Ir}(\mathrm{ppy})_{3}$, the ISC process dominates the deactivation of the $\mathrm{S}_{1}$ state due to the strong spin-orbit coupling effects. See Table S1 in the ESI. $\dagger$ The rate constant 


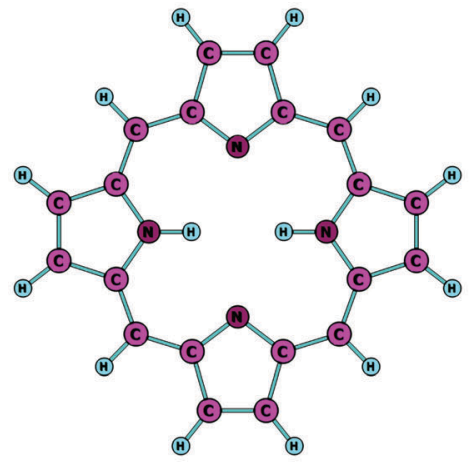

(a)

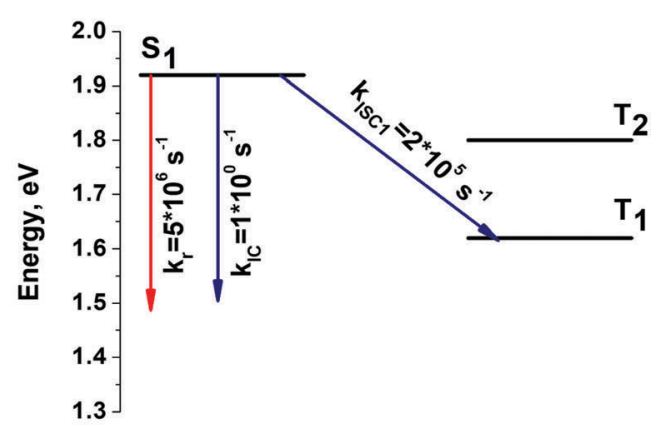

(b)

Fig. 5 (a) The optimized molecular structure of free-base porphyrin $\left(\mathrm{H}_{2} \mathrm{P}\right)$. (b) The energy level diagram for $\mathrm{H}_{2} \mathrm{P}$ including the computed values for the radiative and nonradiative rate constants.

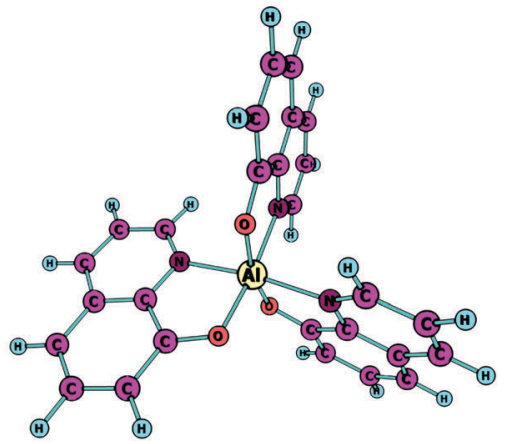

(a)

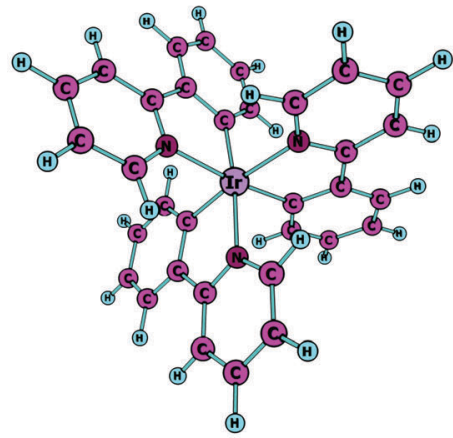

(c)

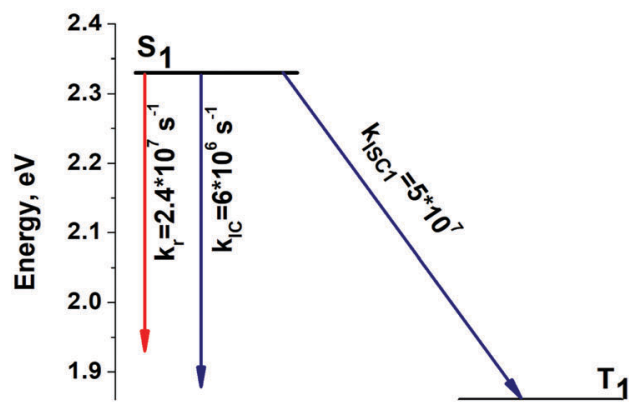

(b)

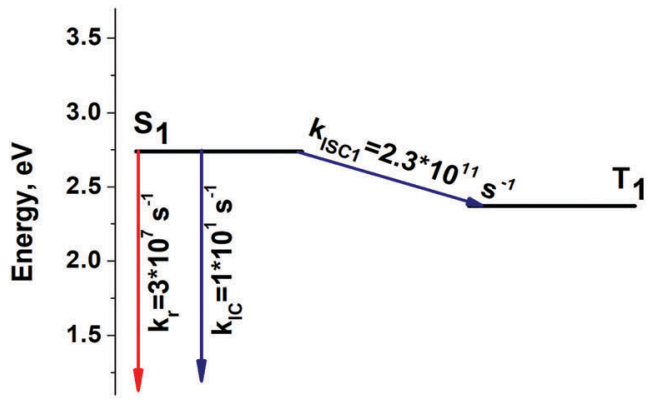

Fig. 6 (a) The optimized molecular structure of fac-Alq 3 . (b) The energy-level diagram for fac-Alq 3 including the computed values for the radiative and nonradiative rate constants. (c) The optimized molecular structure of fac-Ir(ppy) 3 . (d) The energy-level diagram for fac-Ir(ppy) ${ }_{3}$ including the computed values for the radiative and nonradiative rate constants. 


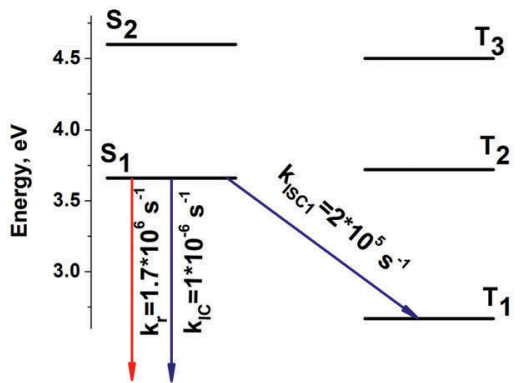

(a)

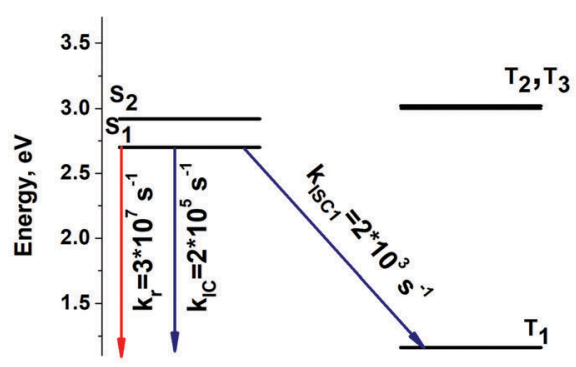

(c)

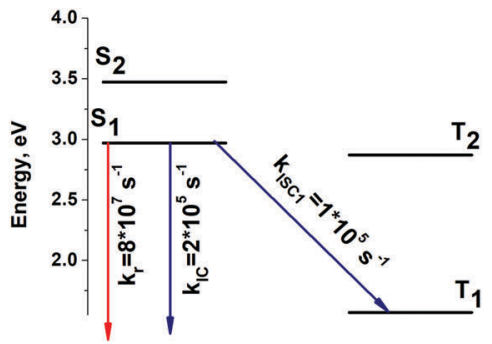

(b)

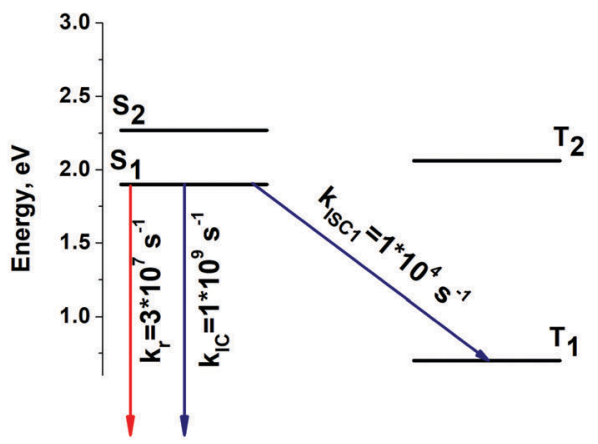

(d)

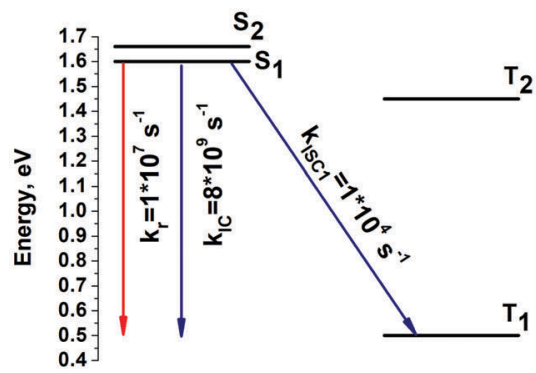

(e)

Fig. 7 The calculated energy levels for (a) naphthalene, (b) anthracene, (c) tetracene, (d) pentacene, (e) hexacene and the computed values of the radiative and nonradiative rate constants.

$k_{\mathrm{ISC} 1}$ is much larger than $k_{\mathrm{r}}$ leading to a very small quantum yield, which agrees with the previously calculated value of about $10^{12} \mathrm{~s}^{-1}$ for $k_{\mathrm{ISC} 1}$ and the experimental results. ${ }^{68}$ The largest $y_{j}$ values and the corresponding vibrational energies $\left(\omega_{j}\right)$ are reported in Table 3. $\mathrm{Alq}_{3}$ has many more vibrational modes with large $y_{j}$ values than $\operatorname{Ir}(\mathrm{ppy})_{3}$, which explains why $\mathrm{Alq}_{3}$ has a larger $k_{\mathrm{IC}}$ rate constant than $\operatorname{Ir}(\mathrm{ppy})_{3}$.

\subsection{Polyacenes}

The energy levels of the lowest singlet and triplet states and the $k_{\mathrm{IC}}$ and $k_{\text {ISC }}$ rate constants of the transitions of the polyacenes are shown in Fig. 7. The calculated excitation energies of the $S_{1}$ and $T_{1}$ states are compared with the experimental data in Table 4.
Table 4 The calculated excitation energies (in eV) of the polyacenes are compared with the experimental data

\begin{tabular}{llll}
\hline Compound & State & XMC-QDPT2 & Exp. $^{a}$ \\
\hline Naphthalene & $\mathrm{S}_{1}$ & $3.66(0.003)$ & 3.86 \\
& $\mathrm{~T}_{1}$ & 2.67 & 2.63 \\
Anthracene & $\mathrm{S}_{1}$ & $2.97(0.2)$ & 3.3 \\
& $\mathrm{~T}_{1}$ & 1.57 & 1.85 \\
Tetracene & $\mathrm{S}_{1}$ & $2.7(0.1)$ & 2.6 \\
& $\mathrm{~T}_{1}$ & 1.16 & 1.26 \\
Pentacene & $\mathrm{S}_{1}$ & $1.9(0.1)$ & 2.1 \\
& $\mathrm{~T}_{1}$ & 0.7 & 0.95 \\
Hexacene & $\mathrm{S}_{1}$ & $1.6(0.1)$ & 1.8 \\
& $\mathrm{~T}_{1}$ & 0.5 & 0.81
\end{tabular}

${ }^{a}$ The experimental data are taken from ref. 37. 
Table 5 Calculated wavenumbers $\left(\omega_{j}\right.$ in $\left.\mathrm{cm}^{-1}\right)$ of the significant vibrational modes for the nonradiative transitions and the corresponding Huang-Rhys factors $\left(y_{j}\right)$ for the $S_{1}$ to $S_{0}$ nonradiative transition of the polyacenes

\begin{tabular}{ll}
\hline Compound & $\omega_{j}\left(y_{j}\right)$ \\
\hline Naphthalene & $519(0.06) ; 775(0.23) ; 1055(0.1) ; 1413(0.36)$ \\
Anthracene & $398(0.37) ; 640(0.02) ; 765(0.02) ; 1039(0.01) ; 1194(0.08) ; 1301(0.16) ; 1443(0.44) ; 1606(0.40)$ \\
Tetracene & $318(0.26) ; 633(0.03) ; 765(0.04) ; 1032(0.01) ; 1190(0.04) ; 1243(0.17) ; 1425(0.15) ; 1441(0.19) ; 1573(0.02) ; 1589(0.25)$ \\
Pentacene & $263(0.18) ; 615(0.02) ; 764(0.05) ; 1190(0.03) ; 1228(0.17) ; 1426(0.24) ; 1449(0.08) ; 1570(0.15)$ \\
Hexacene & $225(0.15) ; 579(0.01) ; 765(0.1) ; 1030(0.01) ; 1183(0.05) ; 1212(0.11) ; 1216(0.01) ; 1217(0.06) ; 1418(0.25) ; 1560(0.06)$
\end{tabular}

The calculated quantum yields $\left(\varphi_{\mathrm{fl}}\right)$ for naphthalene, anthracene, tetracene, pentacene, hexacene, and heptacene are 0.94, 0.99, $0.99,0.03$, and 0.001 respectively, which can be compared with the experimental values of $0.23,0.24,0.21,0.08$, and $0.01 .^{41}$ The calculated quantum yields differ from the experimental ones, whereas a similar trend is obtained for the polyacenes. The calculated $\varphi_{\mathrm{fl}}$ values are not very accurate, because the $\mathrm{S}_{1}$ state is not a pure adiabatic state but consists of a mixture of higher energy states. ${ }^{50}$ The estimated quantum yields $\left(\varphi_{\mathrm{fl}}\right)$ agree qualitatively with the experimental ones only when $k_{\mathrm{IC}}$ is larger than $k_{\mathrm{ISC}}$. For the polyacenes, the calculated $k_{\mathrm{ISC}}$ contribution to the nonradiative rate constant $k_{\mathrm{nr}}$ is underestimated. The calculated $k_{\mathrm{IC}}$ and $k_{\mathrm{ISC}}$ rate constants are expected to be rather accurate, whereas they cannot be used for estimating the quantum yield when $k_{\mathrm{IC}}<k_{\mathrm{ISC}}$. The values of $y_{j}$ and $\omega_{j}$ are of the vibrational modes that are most important for the nonradiative transitions are listed in Table 5. The vibrational mode at about $1400 \mathrm{~cm}^{-1}$ has a $y$ value of about 0.3 for all the polyacenes except for tetracene. This mode yields the main contribution to the $k_{\text {ISC }}$ rate constant. In the calculation of $k_{\text {ISC }}$ for the polyacenes, it is necessary to consider only this mode, as done by Maier and Artyukhov. ${ }^{25-28}$

\subsection{The analysis of nonadiabatic integrals}

Calculations of the nonadiabatic integrals (8) show that the largest integral value of 0.007 a.u. is obtained for the vibrational modes with energies of about $3000 \mathrm{~cm}^{-1}$, because the $y$ value is very small for them. For the other vibrational modes, the integrals (10) are a factor of 2-22 times smaller. The high-frequency modes with $\sim 3000 \mathrm{~cm}^{-1}$ usually correspond to $\mathrm{X}-\mathrm{H}$ stretching vibrations, where $\mathrm{X}=\mathrm{C}, \mathrm{N}, \mathrm{O}$ or another light atom. The present study shows that in the IC channel, the excitation energy of the $S_{1}$ state transforms into stretching vibrations of $\mathrm{X}-\mathrm{H}$ modes, which supports the theory by Plotnikov, Maier and Artyukhov. ${ }^{24-28}$

\section{Summary and conclusions}

The proposed computational approach has been used for calculating the rate constants for internal conversion $\left(k_{\mathrm{IC}}\right)$ and intersystem crossing $\left(k_{\mathrm{ISC}}\right)$ of a number of organic and organometallic compounds. The calculations show that the radiative process dominates for PM567 and AOC. The non-radiative ISC process dominates for psoralene and $\operatorname{Ir}(\mathrm{ppy})_{3}$, whereas the non-radiative IC process dominates for tetraoxa[8]circulene. For $\mathrm{Alq}_{3}$, the rate constants of the radiative and the non-radiative (IC and ISC) processes are of the same size. When the Franck-Condon (FC) and adiabatic approximations are valid, the proposed approach can be used for estimating the fluorescence quantum yield $\left(\varphi_{\mathrm{fl}}\right)$.
For polyacenes and $\mathrm{H}_{2} \mathrm{P}$, it is necessary to go beyond the $\mathrm{FC}$ and adiabatic approximations. The FC approximation breaks down, when the Huang-Rhys factor $(y)$ is about $0.01-0.04$ for modes with energies of about $1000-1800 \mathrm{~cm}^{-1}$ leading to strongly underestimated FC factors. Small values for the FC factor lead to too small calculated values for $k_{\mathrm{IC}}$ and $k_{\mathrm{ISC}}$. The value of $y$ can be used as a criterion for the applicability of our approach. For $\mathrm{H}_{2} \mathrm{P}$, the $y$ value of the vibrational mode at $1393 \mathrm{~cm}^{-1}$ has a small Huang-Rhys factor suggesting that the present approach cannot be applied to free-base porphyrin.

The computations show that in the IC process the excitation energy transfers into the vibrations of the $\mathrm{X}-\mathrm{H}(\mathrm{X}=\mathrm{C}, \mathrm{N}$ and $\mathrm{O})$ bonds supporting the theory by Plotnikov, Maier and Artyukhov. ${ }^{24-28}$ However, when estimating the FC factors of the ISC process, all the vibrational modes have to be taken into account, because many vibrational modes with energies in the range of $1000-1800 \mathrm{~cm}^{-1}$ contribute significantly to the FC factor.

The accuracy of the calculated $k_{\mathrm{IC}}$ and $k_{\mathrm{ISC}}$ rate constants depends strongly on the accuracy of the calculated excitation energies of the excited singlet and triplet states. Since the obtained $k_{\mathrm{IC}}$ and $k_{\mathrm{ISC}}$ rate constants depend strongly on the accuracy of the calculated values for the singlet and triplet excitation energies, we calculated the excitation energies at the XMC-QDPT2 level of theory, which is computationally expensive but a feasible level for molecules of this size. ${ }^{69,70}$

The present approach makes it possible to estimate rate constants for nonradiative transitions $\left(k_{\mathrm{IC}}\right.$ and $\left.k_{\mathrm{ISC}}\right)$ for organic and organometallic compounds within the FC and adiabatic approximation by using calculated values for the matrix elements of the spin-orbit coupling interaction and nonadiabatic coupling interaction.

\section{Conflicts of interest}

There are no conflicts to declare.

\section{Acknowledgements}

The research was carried out using a grant from the Russian Science Foundation (project No. 17-73-20012). This research has been supported by the Academy of Finland through two projects (275845 and 1309394). DS thanks the Magnus Ehrnrooth Foundation for financial support. CSC - the Finnish IT Center for Science - as well as the Finnish Grid and Cloud Infrastructure (persistent identifier urn:nbn:fi:research-infras-2016072533) are acknowledged for computational resources. 


\section{References}

1 C. M. Marian, Wiley Interdiscip. Rev.: Comput. Mol. Sci., 2012, 2, 187-203.

2 N. Boens and M. Ameloot, Int. J. Quantum Chem., 2006, 106, 300-315.

3 D. Beljonne, Z. Shuai, G. Pourtois and J. L. Bredas, J. Phys. Chem. A, 2001, 105, 3899-3907.

4 B. F. Minaev, G. Baryshnikov and H. Ågren, Phys. Chem. Chem. Phys., 2014, 16, 1719-1758.

5 H. Yersin, A. F. Rausch, R. Czerwieniec, T. Hofbeck and T. Fischer, Coord. Chem. Rev., 2011, 255, 2622-2652.

6 A. J. C. Kuehne and M. C. Gather, Chem. Rev., 2016, 116, 12823-12864.

7 T. Mirkovic, E. E. Ostroumov, J. M. Anna, R. van Grondelle, Govindjee and G. D. Scholes, Chem. Rev., 2017, 117, 249-293.

8 V. Ramamurthy and J. Sivaguru, Chem. Rev., 2016, 116, 9914-9993.

9 S. P. McGlynn, T. Azumi and M. Kinoshita, Molecular Spectroscopy of the Triplet State, Englewood Cliffs, New Jersey, 1969.

10 B. Valeur, Molecular Fluorescence: Principles and Applications, Wiley-VCH GmbH, Weinheim (Federal Republic of Germany), 2002.

11 M. Bixon and J. Jortner, J. Chem. Phys., 1968, 48, 715-726.

12 V. G. Plotnikov, V. A. Dolgikh and V. M. Komarov, Opt. Spectrosc., 1977, 43, 522-527.

13 N. P. Gritsan, A. D. Gudmundsdóttir, D. Tigelaar, A. Zhu, W. L. Karney, C. M. Hadad and M. S. Platz, J. Am. Chem. Soc., 2001, 123, 1951-1962.

14 R. A. Caldwell, Laser Flash Photolysis Studies of Intersystem Crossing in Biradicals and Alkene Triplets, in Kinetics and Spectroscopy of Carbenes and Biradicals, ed. M. S. Platz, Springer, Boston, MA, 1990.

15 S. Perun, J. Tatchen and C. M. Marian, ChemPhysChem, 2008, 9, 282-292.

16 J. Tatchen and C. M. Marian, Phys. Chem. Chem. Phys., 2006, 8, 2133-2144.

17 M.-C. Li, M. Hayashi and S.-H. Lin, J. Phys. Chem. A, 2011, 115, 14531-14538.

18 W. Feng, L. Xu, X.-Q. Li, W. Fang and Y. Yan, AIP Adv., 2014, 4, 077131.

19 J. Cao and Z.-Z. Xie, Phys. Chem. Chem. Phys., 2016, 18, 6931-6945.

20 J. C. Vincenta and F. Furche, Phys. Chem. Chem. Phys., 2013, 15, 18336-18348.

21 M. Richter, P. Marquetand, J. González-Vázquez, I. Sola and L. González, J. Chem. Theory Comput., 2011, 7, 1253-1258.

22 B. F. E. Curchod, C. Rauer, P. Marquetand, L. González and T. J. Martínez, J. Chem. Phys., 2016, 144, 101102.

23 J. Li, C.-K. Lin, X. Y. Li, C. Y. Zhu and S. H. Lin, Phys. Chem. Chem. Phys., 2010, 12, 14967-14976.

24 V. G. Plotnikov, Int. J. Quantum Chem., 1979, 16, 527-541.

25 G. V. Maier, V. Y. Artyukhov and N. R. Rib, Russ. Phys. J., 1993, 36, 949-954.

26 V. Y. Artyukhov, A. I. Galeeva, G. V. Maier and V. V. Ponomarev, Opt. Spektrosk., 1997, 82, 520-523.
27 V. Y. Artyukhov and V. A. Pomogaev, Russ. Phys. J., 2000, 43, 590-600.

28 V. A. Pomogaev and V. Y. Artyukhov, J. Appl. Spectrosc., 2001, 68, 251-258.

29 G. V. Baryshnikov, R. R. Valiev, N. N. Karaush, V. A. Minaeva, A. N. Sinelnikov, S. K. Pedersen, M. Pittelkow, B. F. Minaev and H. Agren, Phys. Chem. Chem. Phys., 2016, 18, 28040-28051.

30 R. R. Valiev, Yu. N. Kalugina and V. N. Cherepanov, Spectrochim. Acta, Part A, 2012, 99, 122-125.

31 R. R. Valiev, A. N. Sinelnikov, Y. V. Aksenova, R. T. Kuznetsova, M. B. Berezin, A. S. Semeikin and V. N. Cherepanov, Spectrochim. Acta, Part A, 2014, 117, 323-329.

32 G. V. Baryshnikov, R. R. Valiev, B. F. Minaev and H. Agren, New. J. Chem., 2017, 41, 7621-7625.

33 R. R. Valiev, V. N. Cherepanov, V. Y. Artyukhov and D. Sundholm, Phys. Chem. Chem. Phys., 2012, 14, 11508-11517.

34 R. R. Valiev, E. N. Telminov, T. A. Solodova, E. N. Ponyavina, R. M. Gadirov, G. V. Maier and T. N. Kopylova, Chem. Phys. Lett., 2013, 588, 184-187.

35 N. G. Bryantseva, I. V. Sokolova, R. M. Gadirov, V. P. Khilya and L. Garazd, J. Appl. Spectrosc., 2009, 76, 813-818.

36 B. F. Minaev, G. V. Baryshnikov and V. A. Minaeva, Comput. Theor. Chem., 2011, 972, 68-74.

37 N. Nijegorodov, V. Ramachandran and D. P. Winkoun, Spectrochim. Acta, Part A, 1997, 53, 1813-1824.

38 V. V. N. Ravi Kishore, K. L. Narasimhan and N. Periasamy, Phys. Chem. Chem. Phys., 2003, 5, 1386-1391.

39 J. Fine, K. Diri, A. I. Krylov, C. Nemirow, Z. Lu and C. Wittig, Mol. Phys., 2012, 110, 1849-1862.

40 D. Dolphin, The Porphyrins, Academic Press, New York, 1978.

41 P. W. Atkins and R. S. Friedman, Molecular Quantum Mechanics, Oxford University Press, 1997.

42 R. Send and F. Furche, J. Chem. Phys., 2010, 132, 044107.

43 B. H. Lengsfield and D. R. Yarkony, in State-selected and state-to-state in-molecule reaction dynamics-Part 2, theory, ed. M. Baer and C.-Y. Ng, John Wiley, NY, 1992, ch. 1, pp. 1-71. 44 V. Barone, J. Bloino and M. Biczysko, Vibrationally-resolved electronic spectra in GAUSSIAN 09, June 24, GAUSSIAN 09 Revision A.02, 2010.

45 D. G. Fedorov, S. Koseki, M. W. Schmidt and M. S. Gordon, Int. Rev. Phys. Chem., 2003, 22, 551-592.

46 O. Vahtras and H. Ågren, J. Chem. Phys., 1992, 96, 2118-2126.

47 P. V. Yurenev, M. K. Kretov, A. V. Scherbinin and N. F. Stepanov, J. Phys. Chem. A, 2010, 114, 12804-12816.

48 M. K. Kretov, I. M. Iskandarova, B. V. Potapkin, A. V. Scherbinin, A. M. Srivastava and N. F. Stepanov, J. Lumin., 2012, 132, 2143-2150.

49 M. K. Kretov, A. V. Scherbinin and N. F. Stepanov, Russ. J. Phys. Chem. A, 2013, 87, 245-251.

50 Y. F. Pedash, O. V. Prezhdo, S. I. Kotelevskiy and V. V. Prezhdo, THEOCHEM, 2002, 585, 49-59.

51 M. Casida, Recent Advances in Density Functional Methods Part I, World Scientific, Singapore, 1999, pp. 155-192.

52 C. Lee, W. Yang and R. G. Parr, Phys. Rev. B: Condens. Matter Mater. Phys., 1988, 37, 785-789. 
53 F. Weigend and R. Ahlrichs, Phys. Chem. Chem. Phys., 2005, 7, 3297-3305.

54 J.-D. Chai and M. Head-Gordon, Phys. Chem. Chem. Phys., 2008, 10, 6615-6620.

55 P. J. Hay and W. R. Wadt, J. Chem. Phys., 1985, 82, 299-310.

56 M. J. Frisch, G. W. Trucks, H. B. Schlegel, G. E. Scuseria, M. A. Robb, J. R. Cheeseman, G. Scalmani, V. Barone, B. Mennucci, G. A. Petersson, H. Nakatsuji, M. Caricato, X. Li, H. P. Hratchian, A. F. Izmaylov, J. Bloino, G. Zheng, J. L. Sonnenberg, M. Hada, M. Ehara, K. Toyota, R. Fukuda, J. Hasegawa, M. Ishida, T. Nakajima, Y. Honda, O. Kitao, H. Nakai, T. Vreven, J. A. Montgomery Jr., J. E. Peralta, F. Ogliaro, M. Bearpark, J. J. Heyd, E. Brothers, K. N. Kudin, V. N. Staroverov, R. Kobayashi, J. Normand, K. Raghavachari, A. Rendell, J. C. Burant, S. S. Iyengar, J. Tomasi, M. Cossi, N. Rega, J. M. Millam, M. Klene, J. E. Knox, J. B. Cross, V. Bakken, C. Adamo, J. Jaramillo, R. Gomperts, R. E. Stratmann, O. Yazyev, A. J. Austin, R. Cammi, C. Pomelli, J. W. Ochterski, R. L. Martin, K. Morokuma, V. G. Zakrzewski, G. A. Voth, P. Salvador, J. J. Dannenberg, S. Dapprich, A. D. Daniels, O. Farkas, J. B. Foresman, J. V. Ortiz, J. Cioslowski and D. J. Fox, Gaussian 09, Revision A.1, Gaussian, Inc., Wallingford CT, 2009.

57 A. A. Granovsky, J. Chem. Phys., 2011, 134, 214113.

58 R. R. Valiev, E. N. Telminov, T. A. Solodova, E. N. Ponyavina, R. M. Gadirov, M. G. Kaplunov and T. N. Kopylova, Spectrochim. Acta, Part A, 2014, 128, 137-140.
59 A. A. Granovsky, Firefly version 8.0.0, http://classic.chem. msu.su/gran/firefly/index.html.

60 R. Ahlrichs, M. Bär, M. Häser, H. Horn and C. Kölmel, Chem. Phys. Lett., 1989, 162, 165-169.

61 M. W. Schmidt, K. K. Baldridge, J. A. Boatz, S. T. Elbert, M. S. Gordon, J. H. Jensen, S. Koseki, N. Matsunaga, K. A. Nguyen, S. Su, T. L. Windus, M. Dupuis and J. A. Montgomery, J. Comput. Chem., 2006, 14, 1347-1363.

62 G. V. Baryshnikov, R. R. Valiev, B. F. Minaev and H. Agren, New. J. Chem., 2017, 41, 2717-2723.

63 R. Valiev, I. Benkyi, Y. Konishev, H. Fliegl and D. Sundholm, (to be submitted).

64 S. J. Strickler and R. A. Berg, Chem. Phys. Lett., 1964, 37, 814-822.

65 N. N. Karaush, R. R. Valiev, G. V. Baryshnikov, B. F. Minaev and H. Ågren, Chem. Phys., 2015, 459, 65-71.

66 R. R. Valiev, V. N. Cherepanov, E. G. Ermolina, R. T. Kuznetsova and D. Sundholm, J. Mol. Model., 2013, 19, 4631-4637.

67 F. Santoro, A. Lami, R. Improta, J. Bloino and V. Barone, J. Chem. Phys., 2008, 128, 224311.

68 M. Kleinschmidt, C. van Wüllen and C. M. Marian, J. Chem. Phys., 2015, 142, 094301.

69 T. B. Emelina, A. Y. Freidzon, A. A. Bagaturyants and V. E. Karasev, J. Phys. Chem. A, 2016, 120, 7529-7537.

70 A. Y. Freidzon, A. A. Safonov and A. A. Bagaturyants, J. Phys. Chem. C, 2015, 119, 26817-26827. 